\title{
Huang, Chun-Chieh:
}

\section{Humanism in East Asian Confucian Contexts}

Edited by Jörn Rüsen, Oliver Kozlarek, Jürgen Straub, and Huang Chun-Chieh (165 pages, 2010, transcript Verlag, Bielefeld)

This book deals with the most relevant issue connected to the question of the specific Confucian humanism. Not only many Western, but also several East Asian contemporary scholars are namely still following the presumption according to which humanism is a specific Western concept, deeply rooted in the European intellectual history. The book, written by Professor Huang Chun-Chieh, challenges this Eurocentric presumption and shows through brilliant analyses that humanism can manifest itself in various cultural forms, including the Confucian one. And not only this: the author also clearly illuminates the fact that humanism is not only an inherent part, but rather the very essence of classical Confucian thought, even though it manifests itself in a form that is quite different from the forms that can be found in the extensively individualized contexts of European humanistic tradition.

The author of this book, Prof. Huang Chun-Chieh, is a distinguished National Chair Professor of Ministry of Education, the Dean of the Institute for Advanced Studies in Humanities and Social Sciences at the National Taiwan University (NTU), and the Director of the Program of East Asian Confucianisms at the same academic institution. He is also a research fellow at the Institute of Chinese Literature and Philosophy of the Taiwanese Academia Sinica in Taipei. He is a well-known expert in traditional and modern Confucianism and has written and edited numerous excellent works in this research field.

The book Humanism in East Asian Confucian Contexts was published in English and can thus reach a wider readership in Western, and especially in European academic circles. It consist of 5 chapters and 3 appendices and represents modified and upgraded studies dealing with diverse traditions of East Asian Confucian humanisms.

The author opens every chapter with an introduction which offers the conceptualization and the structure of each topic and closes with a conclusion which summarizes particular cross sections of each delineated content. 
The extensive and very informative introduction guides us through the chapters of the book, offering a brilliant overlook over the crucial concepts in the East Asian Confucian thought. The author places these concepts into a wider cultural context, explaining their developments in the entire geopolitical region which has historically been influenced by Confucianism, focusing upon the area of China, Japan and Korea.

The second chapter, entitled The Unity of Body and Mind, explains the basis of Confucian discourses that manifest themselves through intertwined relations of the human body and the heart-mind (xin) and their connections to the social environment. The author shows why and how this unity is thoroughly representing the basics of Confucian humanist spirit which is rooted in the continuum of mind and body, in the harmony between oneself and the others, in the unity of heaven and humanity, and, above all, in a profound historical consciousness. The bodily recognition of the heart-mind and its relation to the culture and society is essential for the practice of self-cultivation which is a platform for regulation and pacification of "everything that is under Heaven (tianxia)," i.e. of the social order.

In this context, the author refers to Xu Fuguan's concept of mesophysics which places the heart-mind (xin) in the center of human reasoning, allowing men to obtain an insight into the basic cosmic structures, simultaneously offering them possibilities of proper value judgments. Here, Xu follows the Mencian distinction of great and small bodies (dati, xiaoti) which refers to the Confucian binary category of the nobleman (junzi) and small man (xiaoren). Only when reasoning follows the bodily heart-mind, one can become a great human person, the nobleman or junzi. The body is then perceived as a manifestation of spiritual cultivation or the cultivation of humanness (ren). What Mencius called the great body is the reasoning performed by our bodily heart-mind which consists of the enduring quest for self-improvement and self-cultivation. This self-cultivation is regarded as a cultivation of the unity of body and mind.

The third chapter is based on the conceptualization of this unity and places it into its cultural and political context, defining it as the human moral self. The chapter further deals with the relation between the self and the others in terms of intellectual interactions between China and Japan from the $17^{\text {th }}$ century onwards.

The next chapter discusses the relationship between the human person and nature, focusing upon their connection to ren (humanness). Since every human being is an inherent part of nature, as an organic and holistic whole which is 
constantly in dynamic motion, he/she constantly seeks harmony with it. As far as ren (humanness) is immanent in both, the human person and the nature or cosmos, it manifests itself as a moral imperative that strives for the harmonization of personal and cosmic aspects of being. The author exposes the fact that in traditional Confucian discourses, this harmonization should thoroughly be based on the self-realization of the individual moral self. By acting in accordance with humanness (ren), the individual could be united with Heaven/Nature (tian ren heyi) and thus comprehend the genuine meaning and value of existence.

This section is followed by the last, fifth chapter which clarifies some general questions related to the historical consciousness which underlies the theoretical platform of the central topic. Following Qian Mu's interpretation of historical reasoning, the author points out that in order to understand the social, political and cultural background of Confucian humanism, it is by no means sufficient to analyze it merely through the lens of the Aristotelian concept of homo politicus, nor exclusively through the optics of the modern (Western) concept of homo economicus. In this context, the author draws our attention to the fact that humans are both, shaping and being shaped by history; thus, in understanding and interpreting traditional functions of Confucianism, the concept of homo historicus also plays an important role.

The second and the fifth chapter of the book are deepened and explained in a more profound and detailed way by three appendices that follow the last chapter.

The present book is by no means limited to clarifications of the basic concepts delineated above. Moreover, Huang Chun-Chieh's contribution clearly shows that East Asian Confucianisms are, in fact, specific forms of East Asian humanism. The fact that the author gives Confucianism the plural form is linked to the urgent need to highlight that Confucianism is not a monolithic entity, but has various forms in regard to the particular cultural and political backgrounds. Furthermore, the author wants to express the dynamic and creative ability of Confucian thought throughout the East Asian intellectual histories. Prof. Huang's contribution is of great importance to the contemporary understanding of classical and modern Confucian thought and its significance for possible future developments in the global world which is confronted with a profound crisis of values during the last decades.

Tea Sernelj 